\title{
Developing the role of the specialist nurse in contraception and sexual health services
}

Pam Campbell

\section{Background}

The National Health Service (NHS) Plan ${ }^{1}$ demonstrated that nurses need to explore new ways of working in order to deliver responsive and appropriate care in line with the NHS modernisation agenda. Nurses working in specialist services (such as sexual health and contraception) are ideally placed to transform competence into expertise within a defined area and progress to advanced levels of practice, with skills commensurate with most medical colleagues. However, no formal structure for this process exists. This is in contrast to career structures for doctors in sexual health, who undertake core training through the Diploma of the Faculty of Family Planning and Reproductive Health Care (DFFP). Previous articles in this mini-series have noted the slow progress towards nurse-led care in some areas, ${ }^{2,3}$ despite specific direction to expand the role of nurses within the Sexual Health Strategy. ${ }^{4}$

Currently there are isolated 'high-fliers' in nursing who may be fast-tracked into senior clinical positions. However, mechanisms need to be established to make the pathway from basic competence to expert practitioner clear and more attractive to follow.

\section{Career progression \\ Pre-registration level}

One of the first areas to tackle is increasing the exposure to sexual health services within pre-registration nursing courses. Sexual health services can approach Higher Education Institutions (HEIs) to ensure that sexual health has sufficient prominence within the curriculum and to ensure that placements in sexual health services are offered (as either an elective or mainstream choice). This will help raise the profile of sexual health within nursing so that it can be seen as a distinct area for career choice and progression.

\section{Basic level}

The majority of sexual health and family planning services are provided in a non-specialist (general practice) setting. Many practice nurses report having had no formal training in sexual health. Primary Care Trusts could insist that nurses working at this level must access an accredited course that introduces general awareness of sexual health issues. This basic qualification could equip nurses to:

- Provide advice on contraception and safe sex

- Provide emergency contraception

- Signpost patients to appropriate specialist services.

\section{Preliminary level}

Staff working in both genitourinary medicine (GUM) services and family planning clinics (FPCs) have often been attracted to this specialist area of work partly because of regular clinic hours, lack of shift work and lower stress levels than in many acute services. These nurses may not,

J Fam Plann Reprod Health Care 2005; 31(1): 49-50

(Accepted 31 October 2004)

Primary Care Nursing, Staffordshire University, Stafford, UK Pam Campbell, MSc, RGN, Principal Lecturer

Correspondence to: Mrs Pam Campbell, Primary Care Nursing, Staffordshire University, Blackheath Lane, Stafford, Staffordshire ST18 0AD, UK. E-mail: p.k.campbell@staffs.ac.uk therefore, be looking to be catapulted into senior positions involving more responsibility. Such staff will require a slow, structured approach to development, which is based around annual individual performance review (IPR). An initial accredited qualification in family planning and or GUM would be required within 1 year. This would signify the ability to undertake work such as:

- Taking a sexual history and assessing risk

- Cervical screening

- Providing contraceptive advice and some methods of contraception

- Pregnancy counselling/referral

- Testing for sexually transmitted infections (STIs).

\section{Intermediate level}

Following consolidation of skills at the preliminary level, nurses could be encouraged to expand their range of skills within specialist areas. Additional study could focus on defined areas and would necessitate clinical mentorship within the workplace, together with theoretical underpinning obtained under academic guidance. Accreditation could be awarded for distinct areas and could include:

- Assessment and insertion of intrauterine devices

- Menopause advice and management

- Assessment and insertion of hormonal implants

- Assessment and management of psychosexual problems.

\section{Advanced level}

Having gained expertise in specialist areas, some nurses will wish to progress to a more advanced level of practice and possibly achieve consultant status. This will require study at Master's level together with clinical mentorship. Additional study should include learning that enables critique and equips practitioners with research skills. This will ensure that these nurses are continually challenging and expanding evidence-based practice. Skills relating to decision-making, self-awareness and negotiation will encourage political awareness to move the service forwards. Teaching skills will also be required to train junior staff. These nurses would have involvement in setting standards for the service and could choose learning outcomes from a menu which may include:

- Specialist andrology services

- Assessment and management of recurrent STIs

- HIV treatment and care

- Support and guidance for psychosexual services.

\section{Acquiring expertise}

The expectation should, therefore, be that development within the specialty will be incremental, whilst recognising that some nurses will want to fast track. This means that a skills escalator ${ }^{5}$ should be in place for nurses to step on and off, through a process of lifelong learning. The overhaul of the NHS pay system (Agenda for Change) ${ }^{6}$ may facilitate this process with the linking of competencies and skills to remuneration within the Knowledge and Skills Framework. ${ }^{7}$ This system introduces the need for regular IPR and personal development planning. It seeks to link individual and service demands in order to facilitate improvements in patient care. 
Although Trust managers understand that nurses need more education before being able to take on more responsibilities, the demands of a service with limited resources may still compete with the developmental needs of individuals. In order to overcome this rivalry any learning opportunities should be work-based. This does not mean that work-based learning should be limited to inhouse training packages, but that HEIs should be approached to develop accredited programmes that direct learners towards learning opportunities within their practice. These programmes will require mentorship from senior clinicians. Within sexual health, rotational placements (for 6-12 months) could be offered in areas such as GUM, FPCs, menopause clinics, termination of pregnancy services, gynaecology outpatients and teenage outreach clinics (encompassing services designed to reduce teenage pregnancy). Working in these various specialty areas will ensure that clinical experience and competencies are developed, and that their achievement can be demonstrated within portfolios. Registered nurses are required to keep a professional portfolio that demonstrates their learning in practice and which the Nursing and Midwifery Council may request to view every 3 years at the point of re-registration. ${ }^{8}$ Portfolios are an ideal vehicle with which to chart individuals' progression and provide insight into self-awareness of abilities; managers can review them within the IPR when personal development plans are explored ${ }^{7}$ and linked to service requirements Nurses may need some direction regarding demonstration of clinical progression; Campbell et al. ${ }^{9}$ provide such guidance through identifying ways in which nurses can gain insight into their strengths and weaknesses including audit, reflection and peer review.

\section{Introducing change}

The Chief Nursing Officer identified key roles for nurses within the NHS Plan. ${ }^{1}$ These roles include the skills to:

- Run clinics

- Order diagnostic investigations

- Prescribe treatments

- Make and receive direct referrals

- Perform minor surgery and outpatient procedures.

Development programmes could be formulated with these targets identified as ultimate learning (and service) outcomes.

Nurses and doctors working in sexual health services can begin to facilitate change by discussing current working patterns and identifying how they would like these to alter. Doctors should feel less threatened about the expansion of nursing roles because they will have identified the ways in which they can benefit from this (e.g. being freed up to see more complex cases). An initial step may be for nurses to $\log$ data about patients they have seen, noting how many needed to be referred on to the doctor, and why. They could also note the treatment or advice they would have given had there been no doctor available. Similarly, doctors could log the patients they have seen, referred from nurses, and note the treatment or advice that they gave. Analysis of the data from both doctors and nurses will identify just how similar management of patients is between doctors and nurses. An exercise such as this should make nurses think about their capabilities and help doctors identify the skills required for individual nurses' development.

Introducing rotational placements linked to development may require an initial increase in workforce expenditure, particularly as mentorship within these areas will be essential to enable work-based learning to occur. Workforce Development Directorates (now subsumed within Strategic Health Authorities) could logically be approached to contribute to increased costs, as this is clearly linked to their remit of developing the workforce and redesigning services.

\section{Conclusions}

The slow pace of change within sexual health services towards expanded roles for nurses is not unusual or unforeseen. The process of change frequently follows a sluggish pathway, requiring changes in the attitudes and beliefs of grass-roots practitioners before it gathers momentum. As new skills and competencies are acquired, nurses will recognise their abilities and take on more responsibilities that allow them to fulfil their potential. Their goals have already been outlined in national strategies. 1,10 The work that remains to be done is creating structures that move practitioners towards achieving these goals. This requires local discussion and national and international networking to ensure that areas already achieving success with nurse-led services and nurse consultants can guide others along the development path.

Statements on funding and competing interests

Funding. None identified.

Competing interests. None identified.

References

Department of Health. The NHS Plan - A Plan for Investment, A Plan for Reform. London, UK: Department of Health, 2000.

Campbell P. The role of nurses in sexual and reproductive health. $J$ Fam Plann Reprod Health Care 2004; 30: 169-170.

Campbell P. Nurse prescribing for contraceptive care and sexual health. J Fam Plann Reprod Health Care 2004; 30: 255-256.

Department of Health. National Strategy for Sexual Health and HIV. London, UK: Department of Health, 2001.

London, UK: Department of Health, 2001 .
National Health Service (NHS) Modernisation Agency. A Career Framework for the NHS Discussion Document - Version 2. London, UK: NHS Modernisation Agency, 2004

6 Department of Health. Agenda for Change - What Will it Mean for You? A Guide for Staff. London, UK: Department of Health, 2004.

7 Department of Health. The NHS Knowledge and Skills Framework (NHS KSF) and the Development Review Process. London, UK: Department of Health, 2004.

8 Nursing and Midwifery Council. The PREP Handbook. London, UK: Nursing and Midwifery Council, 2001.

Campbell P, Wakley G, Chambers R, Jenkins J. Demonstrating Your Campbell P, Wakley G, Chambers R, Jenkins J. Demonstrating Your
Clinical Competence in Women's Health (Primary Care Nursing Series). Oxford, UK: Radcliffe Medical Press, 2004

10 Department of Health. Developing Key Roles for Nurses and Midwives - A Guide for Managers. London, UK: Department of Health, 2002.

Editor's Note

This is the third and final article in a series of articles looking at aspects of nursing in sexual and reproductive health.

\section{ASSOCIATE MEMBERSHIP OF THE FFPRHC FOR NURSES}

Associate membership of the Faculty of Family Planning and Reproductive Health Care is open to all nurses with a special interest in contraception and reproductive health. The annual subscription is currently $£ 40$. This subscription entitles Associate Members to copies of the Journal of Family Planning and Reproductive Health Care and access to the members' enquiry service.

The associate membership application form can be obtained from the Faculty website at www.ffprhc.org.uk (click on General Training/Training Form). 